\title{
Principal Component and Hierarchical Cluster Analysis of major compounds variation of Moroccan Rosmarinus officinalis essential oil
}

\author{
Saoussan Annemer ${ }^{*}$, Abdellah Farah ${ }^{1}$, Hamide Stambouli ${ }^{2}$, Taoufik Bouayoun ${ }^{2}$, Abdelhakim El ouali lalami $^{1,3}$, and \\ Yassine Ez zoubi ${ }^{1,4}$ \\ ${ }^{1}$ Laboratory of Applied Organic Chemistry, Faculty of Sciences and Technologies, University Sidi Mohammed Ben Abdellah, Fez B \\ P 2202, Morocco \\ ${ }^{2}$ Institute of Forensic Sciences of Gendarmerie Royal, B.P 6597, Rabat-Institute, Morocco \\ ${ }^{3}$ Higher Institute of Nursing Professions and Health Techniques of Fez, Regional Health Directorate, EL Ghassani Hospital, Fez \\ 30000, Morocco \\ ${ }^{4}$ Biotechnology, Environmental Technology and Valorization of Bio-Resources Team, Department of Biology, Faculty of Sciences \\ and Technologies Al-Hoceima, Abdelmalek Essaadi University, Tetouan, Morocco
}

\begin{abstract}
The main compounds or the chemical composition in general is influenced by different factors such as the harvest period, the origin of the plant and the climatic conditions. The composition of Rosmarinus officinalis essential oils during 9 harvest periods (January 2018 to April 2019) was determined by and gas chromatography coupled with mass spectrometry (GC/MS). The main constituents were 1,8Cineole (33.33-52.59\%), Camphor (7.07-20.09\%), $\alpha$-pinene (11.93-16.22\%). Principal Component Analysis (PCA) and Hierarchical Cluster Analysis (HCA) revealed two main groups namely First group "winter season" which contains a high amount of Camphor, Second group "summer season" which has a significant amount of 1,8-Cineole and an intermediate group " which shares the same characterize of the two groups. In conclusion, these results allow us to understand the variation of major compounds according to the seasons for the exploitation of these compounds in different fields.
\end{abstract}

\section{Introduction}

Rosmarinus officinalis is a medicinal plant that belongs to the family Lamiaceae. Commonly known as rosemary and grows widely in the Mediterranean basin [1].

The chemical composition of rosemary essential oil is relatively constant. However, their quantities vary significantly. In general, three major compounds have been identified. 1,8-Cineole as major compound for rosemary from Italy, Tunisia and Morocco). The camphor and borneol which is found in Spain. The $\alpha$ pinene and verbenone present mainly in Corsica, France and Algeria [2]. The main compounds of $R$. officinalis essential oil in Morocco are 1,8-cineole (38-55\%), camphor $(5-15 \%), \alpha$-pinene $(9-14 \%)$, camphene $(2.5-$ $6 \%), \beta$-pinene (4-9\%), bornyl acetate, borneol, verbenone, linalool [3]. There are three chemotypes which is found in the essential oil: $37.4 \% \alpha$-pinene, $41-$ $53 \%$ camphor, and 58-63\% 1,8-Cineole [4]. In the Middle Atlas and Loukkos regions, the presence of 1,8Cineole and camphor in high quantities is notable [5,6].
The content and chemical composition of the essential oil varies according to several factors, the origin [7], the environment [8,9], harvest period [6].

The main objective of this study is to investigate the variation of the major compounds of $R$. officinalis essential oil according to the harvest period by using chemometric techniques, namely principal component analysis and hierarchical cluster analysis.

\section{Materials and methods}

\subsection{Plant material}

The $R$. officinalis samples were collected from Talsint, province of Figuig, Moroccan Oriental (Figure 1), during nine period of harvesting. Doctor Ghanmi Mohammed (ex-researcher at the Forestry Research Center, Rabat, Morocco) carried out botanical identification.

\footnotetext{
* Corresponding author: $\underline{\text { saoussan.annemer@usmba.ac.ma }}$
} 


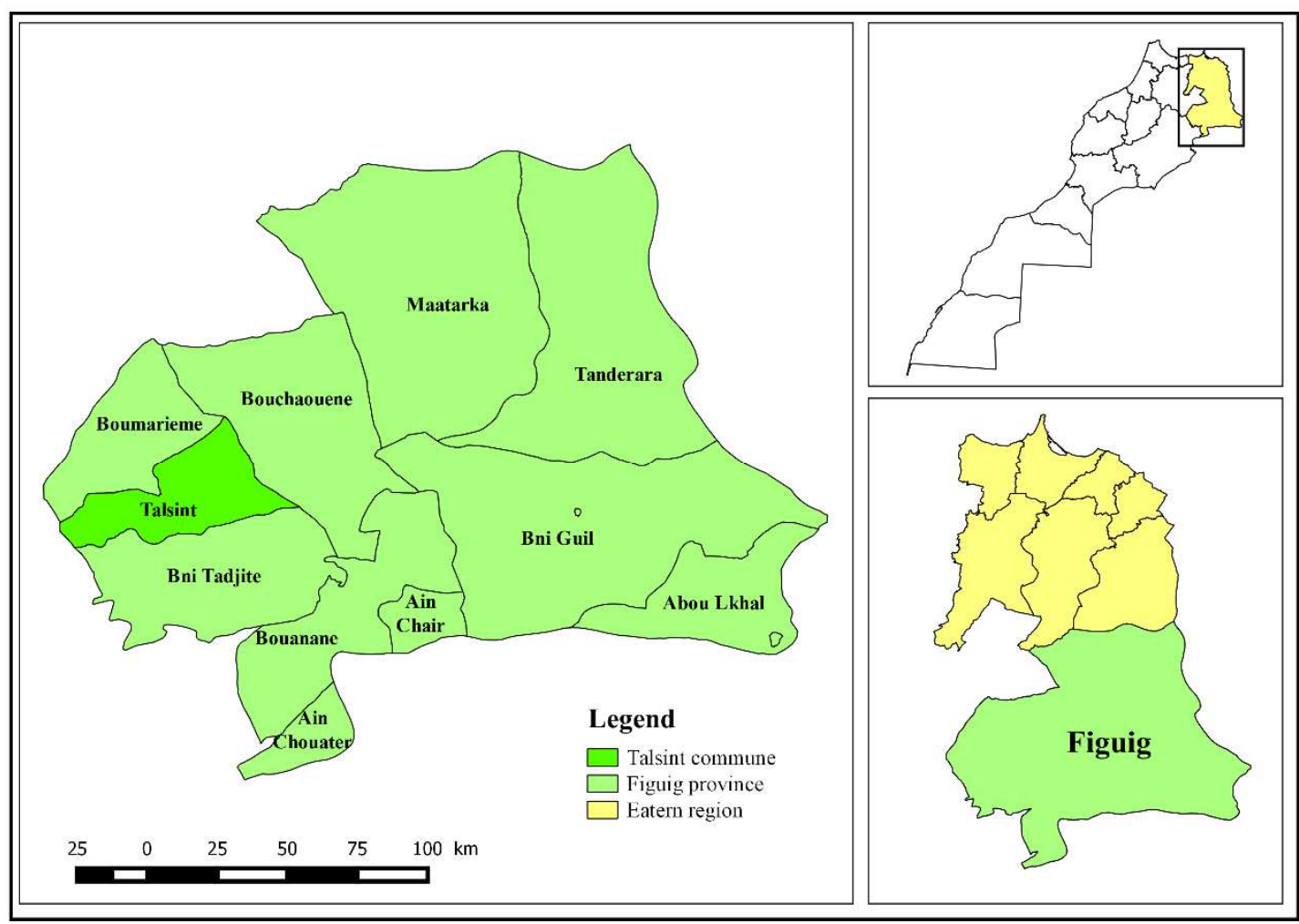

Fig. 1. Geographical localizations of $R$. officinalis. The map was made by QGIS Ver. 2.4.0 Software.

\subsection{Essentialal oils extraction and analysis}

The essential oil was distillated by the Clevenger type apparatus [10] for 3 hours. The essential oil obtained was dried using anhydrous sodium sulfate and then analyzed via Gas Chromatography coupled with mass spectrometry (CG/MS).

Gas Chromatography/Mass Spectrometry (GC/MS) was carried out using a Hewlett-Packard gas Chromatographer (HP 6890) coupled with a mass spectrometer (HP 5973) equipped with an HP-5 capillary column $(30 \mathrm{~m} \times 0.25 \mathrm{~mm}$, film thickness of $0.25 \mu \mathrm{m}$ ). The carrier gas was He at $1.5 \mathrm{ml} / \mathrm{min}$ using a split mode ratio of $1 / 50$. The injection was added manually with an injected volume of $1.2 \mu \mathrm{l}$ and the injector temperature was fixed at $275^{\circ} \mathrm{C}$, where the oven temperature programmed from $50^{\circ} \mathrm{C}$ to $250^{\circ} \mathrm{C}$ at $4^{\circ} \mathrm{C} / \mathrm{min}$. the ion source temperature was $230^{\circ} \mathrm{C}$, with ionization voltages of $70 \mathrm{eV}$ and the scan mass range was $35-450$ atomic mass units.

\subsection{Statistical analysis}

The principal component analysis (PCA) and hierarchical cluster analysis (HCA) were performed with JMP Pro 14 software.

\section{Results and discussion}

The results of major constituents were detected eight compounds in $R$. officinalis essential oils. These eight compounds were 1,8-Cineole (33.33-52.59\%), Camphor (7.07-20.09\%), $\alpha$-pinene (11.93-16.22\%), $\beta$ pinene (5.05-7.45\%), Camphene (3.23-5.06\%), Myrcene (1.68-4.54\%), limonene $(0.83 \%-3.32 \%) \mathrm{m}$ and $\alpha$-Terpinolene $(0.86-2.06 \%)$. Our results Very similar to Sabbahi et al. [11] results who found that rosemary from Talsint (Province of Figuig, Oriental region of Morocco) was characterized by the 1,8-cineole, followed by the camphor, and the $\alpha$-pinene. In addition, Hannour et al. [5] reported the major compounds as 1,8-cineole chemotype (46.23\%), and camphor chemotype $(17.29 \%)$ of rosemary essential oils from Middle Atlas Mountains, Morocco. Furthermore, The main components of $R$. officinalis found by Bouyahya et al. [12] were 1,8-cineole (23.67\%), camphor (18.74\%), borneol $(15.46 \%)$, and $\alpha$-pinene $(14.08 \%)$ in rosemary from the Ouezzan Province, north of Morocco. Several factors reported in literature can modify the chemical composition, and the major compounds such as: the harvest period [6], the method of extraction [13], the environmental condition $[14,15]$, the harvest stages [16], the site of collect [7], and the genotype of the plant [17]. 
Table 1. The major compounds of $R$. officinalis essential oils from each harvest period. Pn: harvest period.

\begin{tabular}{|c|c|c|c|c|c|c|c|c|c|}
\hline $\begin{array}{c}\text { Harvest } \\
\text { period }\end{array}$ & Dates & $\begin{array}{c}\alpha- \\
\text { pinene }\end{array}$ & Camphene & $\begin{array}{c}\beta- \\
\text { pinene }\end{array}$ & Myrcene & Limonene & $\begin{array}{c}1,8- \\
\text { cineole }\end{array}$ & Camphor & $\alpha$-Terpineol \\
\hline $\mathrm{P} 1$ & 21/01/2018 & 16.22 & 4.59 & 5.17 & 2.54 & 0.83 & 33.88 & 18.66 & 0.87 \\
\hline $\mathrm{P} 2$ & 28/03/2018 & 15.76 & 5.59 & 6.16 & 3.54 & 2.04 & 40.48 & 15.97 & 2.75 \\
\hline P3 & $20 / 05 / 2018$ & 12.11 & 3.59 & 7.05 & 4.54 & 2.00 & 52.59 & 7.82 & 1.55 \\
\hline $\mathrm{P} 4$ & 01/07/2018 & 11.93 & 3.23 & 7.05 & 2.54 & 2.49 & 49.92 & 8.29 & 1.36 \\
\hline P5 & 03/09/2018 & 13.11 & 3.23 & 7.45 & 1.68 & 1.94 & 43.33 & 7.82 & 1.26 \\
\hline P6 & $24 / 10 / 2018$ & 16.16 & 4.56 & 5.45 & 2.68 & 1.94 & 38.33 & 19.09 & 0.86 \\
\hline P7 & $18 / 12 / 2018$ & 16.06 & 4.44 & 5.05 & 2.68 & 1.94 & 33.33 & 20.09 & 0.86 \\
\hline P8 & 06/02/2019 & 16.06 & 5.06 & 5.43 & 2.08 & 0.94 & 33.83 & 19.09 & 0.86 \\
\hline P9 & 06/04/2019 & 13.02 & 4.59 & 7.05 & 2.54 & 3.32 & 44.41 & 7.07 & 2.06 \\
\hline
\end{tabular}

\subsection{Principal components analysis}

\subsubsection{Contribution of principal components and explained variability}

In order to identify correlations between major compounds and similar periods, a principal component analysis was performed using eight major compounds and during nine harvest periods. Table 2 represents the eigenvalues, the percentage of explained variability and cumulated percentage of eight components. The two first components showed an eigenvalues higher than 1 (according to [18] the components whose eigenvalues are higher than 1 must keep it). Therefore, the number of components retained to explain the majority of the variables are two principal components which explained $82.71 \%$ of the variability. The first components (PC 1) explained $62.19 \%$ and the second component (PC 2) explained $20.52 \%$ of the variability.

The figure 2 illustrates the contribution of the three fist components to explain the variables (major compounds). The first components contributed by $\alpha$ pinene, 1,8-Cineole, camphor, and $\beta$-pinene. The second contributed by camphene and $\alpha$-Terpineol. The third component contributed by Myrcene. 
Table 2. Eigenvalues, percentages of variability explained, and cumulated percentages of the three first components.

\begin{tabular}{cccc}
\hline $\begin{array}{c}\text { Principal } \\
\text { Components }\end{array}$ & Eigen values & $\begin{array}{c}\text { Percentages of } \\
\text { explained } \\
\text { variability (\%) }\end{array}$ & $\begin{array}{c}\text { Cumulated } \\
\text { percentages (\%) }\end{array}$ \\
PC 1 & 4.97 & 62.19 & 62.19 \\
PC 2 & 1.64 & 20.52 & 82.71 \\
PC 3 & 0.88 & 11.04 & 93.75 \\
PC 4 & 0.37 & 4.56 & 98.31 \\
PC 5 & 0.07 & 0.82 & 99.13 \\
PC 6 & 0.04 & 0.49 & 99.62 \\
PC 7 & 0.03 & 0.31 & 99.94 \\
PC 8 & 0.01 & 0.06 & 100.00 \\
\hline
\end{tabular}

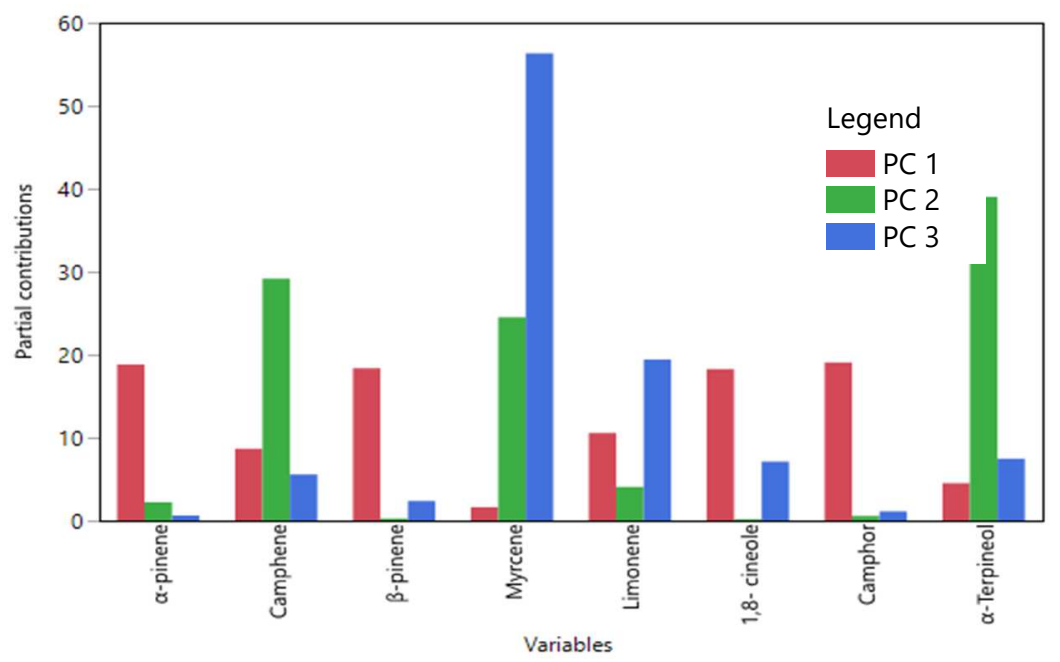

Fig.2. Contribution of the first three principal components to the variable explanation (major compound). PC: principal component.

\subsubsection{Variables and individuals study by principal component analysis}

The Figure 3 represents the projection of the variables on the first and second principal component (PC). The loading plot shows that there is some correlation. A positive correlation between Camphor and $\alpha$-pinene (0.96), 1,8-Cineole and $\beta$-pinene (0.87), $\alpha$-pinene and camphene (0.77), as well as a negative correlation between 1,8-Cineole and Camphor (-0.89), 1,8-Cineole and $\alpha$-pinene $(-0.93), \alpha$-pinene and $\beta$-pinene $(-0.92), \beta$ pinene and Camphor (-0.98). The figure 4 illustrates the projection of the individuals and variables on the PC1 and PC2. The Biplot was indicated a formation of two main groups: the first group is formed by the months "October; December; January; February" indicates the winter season, the second group is formed by the months
"April; May; July; September" features the summer season, and an intermediate group is formed by the month "March" that share the same characterize of the two seasons.

The Biplot also showed that the first group is characterized by a richness in Camphor and $\alpha$-pinene compounds especially the individuals corresponding to the months December and February, the second group featured by an important amount of 1,8-Cineole and $\beta$ pinene compound, and the intermediate group by an average amount of Camphor and $\alpha$-pinene, $\beta$-pinene and 1,8-Cineole compounds. Melito et al. [19] reported that the chemical composition of $R$. officinalis was significantly affected by the seasons. They also stated that the $\beta$-pinene and bornyl acetate compounds were the highest in spring, and $\gamma$-terpinene as well as terpinolene compounds were high in summer and the lowest in winter. However, Ismaili et al. [20] indicated 
that the chemical composition did not change in different seasons.

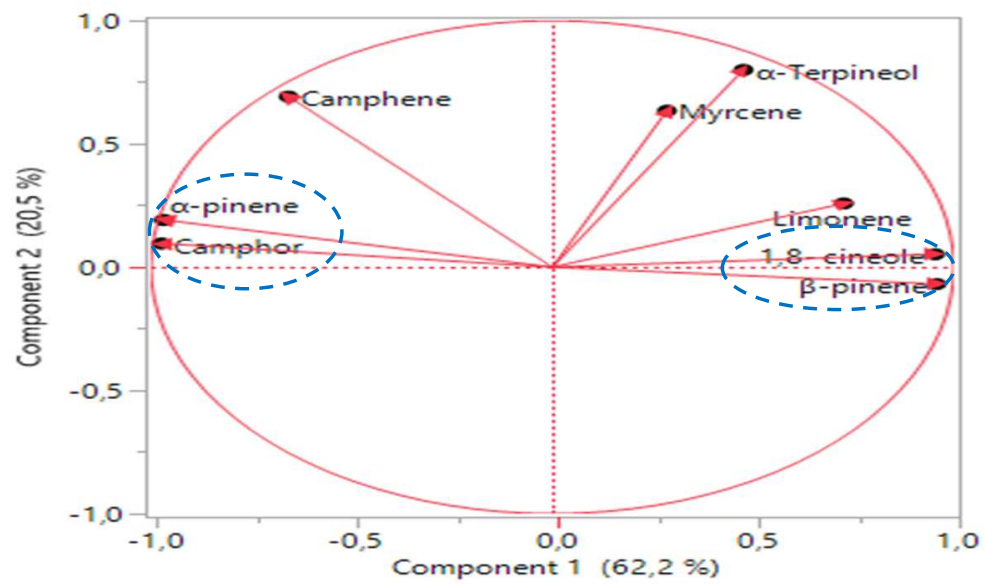

Fig. 3. Loading plot obtained by principal component analysis of the major compounds of $R$. officinalis.

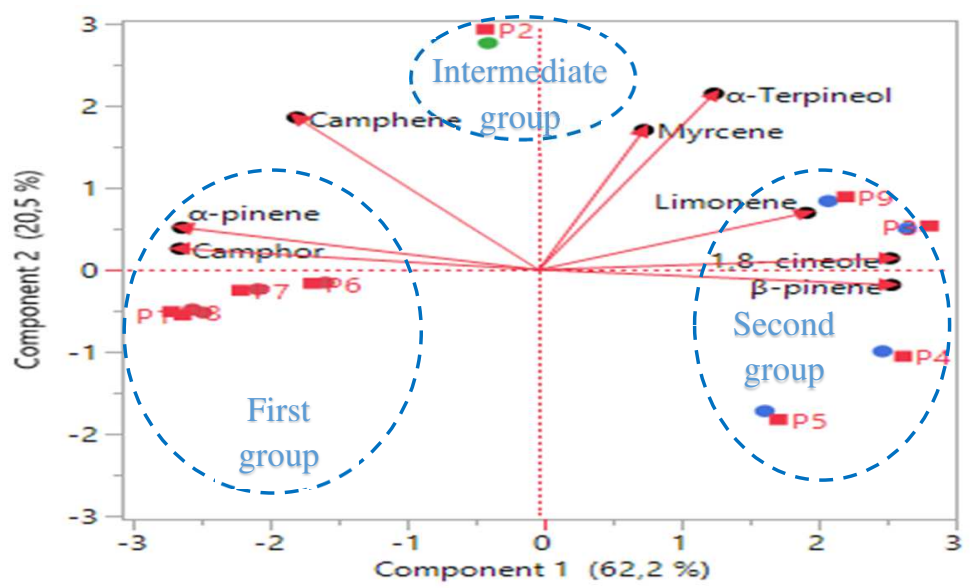

Fig. 4. Biplot obtained by principal component analysis of the major compounds of $R$. officinalis. Pn: harvest period.

\subsection{Hierarchical cluster analysis}

The results of the hierarchical cluster analysis (figure 5) was revealed a clear differentiation between the groups. The first group represented winter season (P1, P6, P7, $\mathrm{P} 8)$, the other group characterized summer season (P3, P4, P5, P9), and an intermediate group between the two groups (P2) that formed separate clusters.

In the first group (the winter season), the amount of $\alpha$-pinene and camphor took maximum values (in red), while 1,8-Cineole and $\beta$-pinene took minimum values (in blue). In the second group (summer season) represents the opposite of the first group, $\alpha$-pinene and camphor were minimal (in blue), while 1,8-Cineole and $\beta$-pinene were maximal (in red). Regarding the intermediate group, it shares the same characteristics of the two groups with an average amounts of 1,8-Cineole, $\beta$-pinene, $\alpha$-pinene and camphor. 


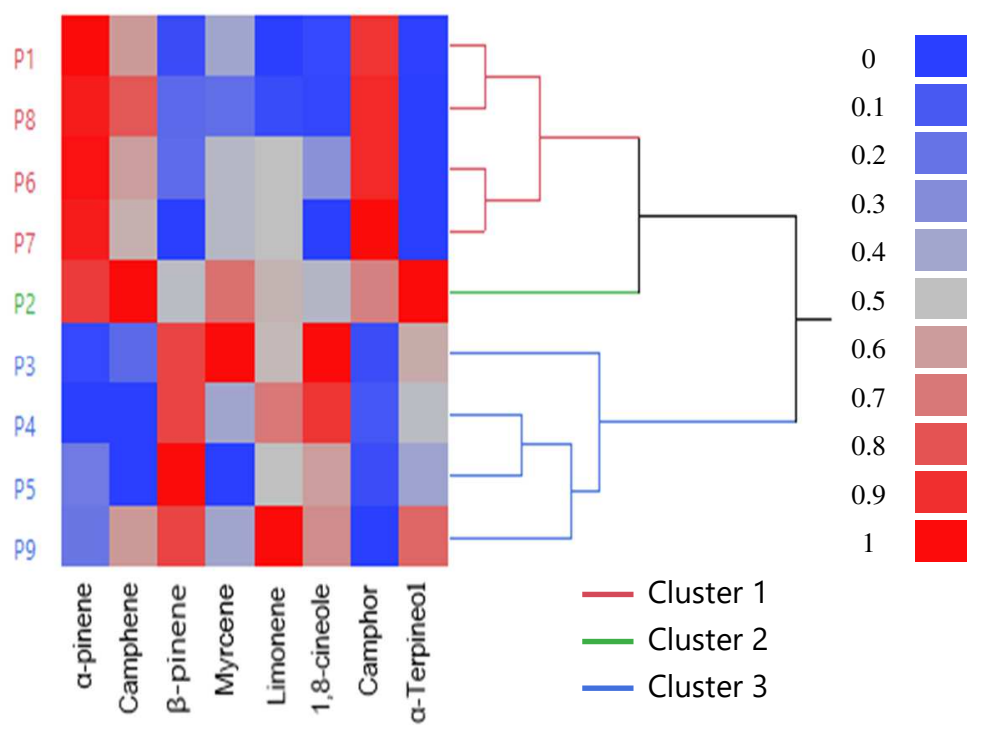

Fig. 5. Cluster analysis of the major compounds of $R$. officinalis essential oils. Cluster: group.

\section{Conclusion}

This study is based on the harvest period effect on the variation of the major compounds of $R$. officinalis essential oil. The principal component analysis showed that there are some correlations between the variables studied. A strong positive correlation between the variables $\beta$-pinene and 1,8-cineole, Camphor and $\alpha$ pinene, whereas a strong negative correlation between 1,8-Cineole and Camphor, 1,8-Cineole and $\alpha$-pinene, $\alpha$ pinene and $\beta$-pinene, $\beta$-pinene and Camphor. On the other hand, it identified two main groups of individuals, the first group "winter season", the second group "summer season" and the intermediate group. PCA and HCA confirm that the amount of major compounds is significantly affected by the harvest period.

\section{References}

1. A. Rašković, I. Milanović, N. Pavlović, T.

Ćebović, S. Vukmirović, and M. Mikov, BMC Complement. Altern. Med. 14, (2014)

2. S. Zrira, Med. Aromat. Plants World - Africa 3, 91 (2017)

3. D. J. Charles and D. J. Charles, Antioxid. Prop. Spices, Herbs Other Sources 495 (2013)

4. M. D. Hernández, J. A. Sotomayor, Á. Hernández, and M. J. Jordán, Essent. Oils Food Preserv. Flavor Saf. 677 (2016)

5. K. Hannour, A. Boughdad, A. Maataoui, and A. Bouchelta, Int. J. Trop. Insect Sci. 38, 192 (2017)

6. J. M. Andrade, C. Faustino, C. Garcia, D. Ladeiras, C. P. Reis, and P. Rijo, Futur. Sci. OA 4, (2018)

7. P. A. Riabov, D. Micić, R. B. Božović, D. V. Jovanović, A. Tomić, O. Šovljanski, S. Filip,
T. Tosti, S. Ostojić, S. Blagojević, and S. Đurović, Ind. Crops Prod. 151, (2020)

8. Y. Li, D. Kong, Y. Fu, M. R. Sussman, and H. Wu, Plant Physiol. Biochem. 148, 80 (2020)

9. H. El-Zaeddi, Á. Calín-Sánchez, L. NogueraArtiaga, J. Martínez-Tomé, and Á. A. Carbonell-Barrachina, Sci. Hortic. (Amsterdam). 267, (2020)

10. J. F. Clevenger, J. Pharm. Sci. 17, 345 (1928)

11. M. Sabbahi, A. El Hassouni, A. Tahani, and A. El Bachiri, J. Chem 8, 866 (2020)

12. A. Bouyahya, A. Et-Touys, Y. Bakri, A. Talbaui, H. Fellah, J. Abrini, and N. Dakka, Microb. Pathog. 111, 41 (2017)

13. D. Sadeh, N. Nitzan, D. Chaimovitsh, A. Shachter, M. Ghanim, and N. Dudai, Ind. Crops Prod. 138, (2019)

14. D. V Lakušiclakušicá, M. S. Ristic’b, R. Ristic`b, V. N. Slavkovska, J. B. S ` InžarSekulicásekulicá, and B. S. Lakušiclakušic’*, Environment-Related Variations of the Composition of the Essential Oils of Rosemary (Rosmarinus Officinalis L.) in the Balkan Penninsula (n.d.)

15. Y. Li, D. Kong, Y. Fu, M. R. Sussman, and H. Wu, Plant Physiol. Biochem. 148, 80 (2020)

16. W. Yeddes, W. Aidi Wannes, M. Hammami, M. Smida, A. Chebbi, B. Marzouk, and M. Saidani Tounsi, J. Essent. Oil-Bearing Plants 21, 972 (2018)

17. C. Formisano, S. Delfine, F. Oliviero, G. C. Tenore, D. Rigano, and F. Senatore, Ind. Crops Prod. 63, 256 (2014)

18. D. A. Jackson and D. A. Jackson2, Source Ecol. 74, 2204 (1993) 
19. S. Melito, G. L. Petretto, S. Chahine, G.

Pintore, and M. Chessa, Nat. Prod. Commun.

14, (2019)

20. M. R. Ismaili, M. Rahouti, B. Kabouchi, H.

Ramzi, M. Aberchane, A. Fidah, A. Famiri,

and O. Lamzoudi, J. Essent. Oil-Bearing Plants

20, 1266 (2017) 